\title{
ОСОБЕННОСТИ ЭНЕРГЕТИЧЕСКОГО ОБМЕНА, КОМПОЗИЦИОННОГО СОСТАВА ТЕЛА И РАЗВИТИЯ МЕТАБОЛИЧЕСКИХ НАРУШЕНИЙ У ДЕТЕЙ С ПРОСТЫМ ОЖИРЕНИЕМ И КОНСТИТУЦИОНАЛЬНОЙ ВЫСОКОРОСЛОСТЬЮ
}

\author{
П.Л. Окороков', О.В. Васюкова' \\ ${ }^{1}$ Национальный медицинский исследовательский центр эндокринологии, Москва, Россия
}

ВВЕДЕНИЕ: Развитие простого (конституционально-экзогенного) ожирения в детском возрасте как правило характеризуется нормальными или высокими показателями роста. При сопоставимых значениях SDS ИМТ дети с высокорослостью и нормальным ростом могут иметь различия в композиционном составе тела, что в свою очередь может влиять на состояние энергетического обмена и развитие метаболических нарушений/

ЦЕЛЬ: Сравнить показатели основного обмена, параметры композиционного состава тела и частоту метаболических нарушений у детей с простым ожирением в зависимости от наличия конституциональной высокорослости.

МАТЕРИАЛЫ И МЕТОДЫ: В Исследование включено 165 детей в возрасте от 8 до 14 лет с простым ожирением (средний возраст 12,8 [11,3;13,9] лет; SDS ИМТ 3,2 [2,9;3,6]), разделенных на две группы: в исследуемую группу вошли 82 ребенка с конституциональной высокорослостью (SDS роста $+2,6[2,2 ; 3,0])$. Группу контроля составили 83 ребенка с нормальными показателями роста (SDS роста $+1,1$ [2,2;3,0]). Высокорослость определялась как SDS роста > 2,0, согласно критериям ВОЗ. Всем детям проведена оценка композиционного состава тела (методом биоимпедансного анализа), основного обмена (методом непрямой респираторной калориметрии) и скрининг метаболических нарушений, ассоциированных с ожирением. Дислипидемия диагностировалась при повышении уровня общего холестерина $\geq 5,2$ ммоль/л или повышении уровня триглицеридов $\geq 1,7$ ммоль/л (для детей старше 10 лет). Состояние углеводного обмена оценивали по результатам ОГТТ с глюкозой из расчета 1,75 г/кг, но не более 75 г сухого вещества на основании рекомендаций ВОЗ (1998). Нормальной считалась концентрация глюкозы в венозной плазме натощак $<6,1$ ммоль/л; глюкоза венозной плазмы на 120 мин ОГТТ <7,8 ммоль/л. Инсулинорезистентность (ИР) диагностировалась при ISI Matsuda <2,6. Наличие неалкогольной жировой болезни печени оценивалось по данным УзИ. Статистическая обработка данных проводилась с использованием пакета прикладных программ Statistica (StatSoftInc., USA, version 10.0). Так как большинство изучаемых показателей не имело приближенно-нормального распределения, все данные представлены в виде медианы и интерквартильного размаха. Для оценки достоверности различий количественных признаков между изучаемыми группами использовался критерий Манна-Уитни и дисперсионный анализ Краскела-Уоллеса. Для оценки достоверности различий качественных признаков между изучаемыми группами были построены таблицы сопряженности с их последующей оценкой по методу Пирсона.

РЕзУЛЬтАТЫ: Исследуемы группы были сопоставимы по полу, возрасту и SDS ИMT, на статистически значимо различались по росту и SDS роста (см. табл.1).

Таблица 1. Клиническая характеристика исследуемых групп

\begin{tabular}{lccc}
\hline & $\begin{array}{c}\text { Ожирение } \\
\text { с высокорослостью }\end{array}$ & $\begin{array}{c}\text { Ожирение с нормальными } \\
\text { показателями роста }\end{array}$ & p \\
\hline Возраст, годы & $12,4[10,6 ; 14,5]$ & $12,7[11,8 ; 13,8]$ & 0,57 \\
Пол: м/ж & $41 / 41$ & $38 / 45$ & 0,56 \\
Рост, См & $171,4[160,1 ; 178,2]$ & $160,5[155,3 ; 165,5]$ & $<0,0001$ \\
SDS роста & $2,26[2,2 ; 3,1]$ & $1,0[0,23 ; 1,53]$ & $<0,0001$ \\
Вес, кг & $95,5[77,5 ; 120]$ & $86,0[72,9 ; 109]$ & 0,24 \\
ИМТ, кг/м² & $33,9[29,3 ; 36,9]$ & $33,5[30,2 ; 36,4]$ & 0,78 \\
SDS ИМТ & $3,2[2,8 ; 3,5]$ & $3,2[2,9 ; 3,6]$ & 0,45 \\
\hline
\end{tabular}




\section{СБОРНИК ТЕЗИСОВ}

XVII Российская научно-практическая конференция детских эндокринологов «Достижения науки в практику детского эндокринолога»

Оценка энергетического обмена выявила статистически значимое повышение основного обмена у детей с ожирением и конституциональной высокорослостью по сравнению с контрольной группой (1989 [1693;2294] vs 1883 [1618;2066] ккал/сут; p=0,001). При оценке композиционного состава тела продемонстрировано, что дети с ожирением и высокорослостью характеризуются меньшим количеством жировой ткани по сравнению с контрольной группой $(44,6 \%$ [39,8;50,4] vs 42,1\% [38,0; 47,7]; p=0,04) при сопоставимых значениях SDS ИМТ. Скрининг метаболических нарушений выявил сопоставимую распространенность метаболических нарушений при простом ожирении, независимо от наличия высокорослости (см. табл.2).

Таблица 2. Частота метаболических нарушений в исследуемых группах

\begin{tabular}{|c|c|c|c|}
\hline & $\begin{array}{c}\text { Ожирение с } \\
\text { высокорослостью }\end{array}$ & $\begin{array}{c}\text { Ожирение с нормальными } \\
\text { показателями роста }\end{array}$ & $\mathbf{P}$ \\
\hline Дислипидемия, \% & 39,1 & 41,1 & 0,76 \\
\hline $\begin{array}{l}\text { Нарушение толерантности } \\
\text { к глюкозе, \% }\end{array}$ & 13,4 & 16,5 & 0,34 \\
\hline Инсулинорезистентность, \% & 73,1 & 75,3 & 0,65 \\
\hline $\begin{array}{l}\text { Неалкогольная жировая } \\
\text { болезнь печени, \% }\end{array}$ & 56,4 & 59,3 & 0,57 \\
\hline
\end{tabular}

ЗАКЛЮЧЕНИЕ: Для детей с простым ожирением и конституциональной высокорослостью характерны более высокие абсолютные значения основного обмена и большее количество тощей массы по сравнению со сверстниками с нормальными показателями роста. Наличие конституциональной высокорослости не влияет на частоту метаболических нарушений, ассоциированных с ожирением. Данные особенности необходимо учитывать при планировании скрининга ассоциированных с ожирением заболеваний у детей с конституциональной высокорослостью.

КЛЮЧЕВЫЕ СЛОВА: детское ожирение; основной обмен; композиционный состав тела, конститучиональная высокорослость 